\title{
HUBUNGAN DUKUNGAN SOSIAL SUAMI DENGANKEAKTIFAN IBU MEMBAWA BALITA KE POSYANDU DAHLIA II DI DUSUN PULO LAPANGAN DESA PULO LOR KECAMATAN JOMBANG KABUPATEN JOMBANG
}

\author{
The Correlation of Husband 's Social Support With Mother's Activeness \\ to Bring Toddler to Posyandu Dahlia 2 at Pulo Lapangan Sub Village \\ Pulo Lor Village Jombang Subdistrict in Jombang District
}

\author{
Siska Puspitasari ${ }^{1}$, Rifa'i $^{2}$, Anis Satus Syarifah ${ }^{3}$ \\ ${ }^{1}$ Program studi S1 Keperawatan STIKES Pemkab Jombang \\ ${ }^{2}$ Program studi S1 Keperawatan STIKES Pemkab Jombang \\ ${ }^{3}$ Program studi Profesi Ners STIKES Pemkab Jombang \\ Email: siska@yahoo.com
}

\begin{abstract}
ABSTRAK
Dukungan sosial dari suami sangat diperlukan agar ibu aktif mengikuti kegiatan posyandu. Kebanyakan ibu jarang membawa balitanya ke posyandu karena pemberian imunisasi sudah lengkap, sehingga menyebabkan ibu tidak aktif membawa balita ke posyandu. Saat ini dukungan sosial suami dibutuhkan. Seorang suami harus meyakinkan ibu bahwa kegiatan posyandu sangat penting bagi kesehatan tumbuh kembang balita. Dengan demikian penelitian ini bertujuan untuk mengetahui hubungan dukungan sosial suami dengan keaktifan ibu.

Desain penelitian yang digunakan dalam penelitian ini adalah kuantitatif analitik korelasi dengan pendekatan cross sectional. Populasi dalam penelitian ini adalah ibu yang mempunyai balita di Dusun Pulo Lapangan Desa Pulo Lor Kecamatan Jombang yaitu sejumlah 93 responden. Sampel dalam penelitian adalah 47 responden. Teknik sampling yang digunakan adalah simple random sampling. Variabel penelitian ini adalah hubungan dukungan sosial suami dengan keaktifan ibu membawa balita ke posyandu. Pengumpulan data menggunakan kuesioner dan KMS. Analisa data dengan cara uji statistik chi-aquare.

Berdasarkan hasil penelitian yang telah dilakukan didapatkan hampir seluruh dukungan sosial suami baik yaitu 76,6\%, sedangkan keaktifan ibu membawa balita ke posyandu sebagian besar aktif yaitu 74,5\%.

Dengan demikian perlu adanya peningkatan keaktifan ibu dalam membawa balita ke posyandu dengan cara orang yang paling dekat atau petugas kesehatan berpartisipasi untuk memberikan penyuluhan kesehatan tentang tumbuh kembang balita secara rutin agar masyarakat dapat menambah wawasan dalam kehidupan sehari-hari.
\end{abstract}

Kata kunci : dukungan sosial suami, keaktifan, posyandu

\begin{abstract}
Social support from husband is very needed in order that mother is active to participate in Posyandu activities. The most mothers rarely bring their toddlers to Posyandu because giving immunization has been complete, so that it causes that the mothers are not active to bring toddlers to Posyandu. At this moment, husband's social support is needed. A husband should convince the mother that The Posyandu activity is very important for the health of toddler's growth. Thus this research aimed to determine the correlation of husband's social support with the mother's activeness.

The research design used quantitative analytic correlation with cross sectional approach. The population in this research was the mothers who had toddlers at Pulo Lapangan Sub Village ,Pulo Lor Village, Jombang Sub district, as many as 93 respondents. The samples in this research were 47 respondents. The sampling technique was simple random sampling. The variable of this research was the correlation of husband's social support with mother's activeness to bring toddler to Posyandu. Data collection used questionnaires and KMS. Data analysis used chi-square statistical test.

Based on the result of research which has been done that almost all social support of husbands were good $76,6 \%$, whereas the activeness of the most mothers who brought toddler to Posyandu were active 74,5 Thus, it is necessary to increase the activeness of mother to bring toddler to Posyandu by the way
\end{abstract}


of the closest person or health officer who participate to give health education about toddler's growth regularly in order that society can add perception in daily life.

\section{Keywords: Husband 's social Support, , mother's ctiveness, Posyandu}

\section{PENDAHULUAN}

Salah satu usaha kesehatan bersumber daya masyarakat yang memiliki peran signifikan dalam pemberdayaan masyarakat untuk meningkatkan derajat kesehatan masyarakat adalah Posyandu. Menurut Seno (2008) faktor yang berhubungan dengan keaktifan ibu menimbangkan balita di Posyandu adalah pendidikan, pengetahuan, dukungan, status pekerjaan, tapi dukungan suami yang masih kurang berperan aktif terhadap kegiatan Posyandu yang ada di lingkungan masyarakat menjadi satu kendala dalam pelaksanaan kegiatan tersebut. Ketidakaktifan ibu balita ke Posyandu dapat dipengaruhi oleh kurangnya dukungan. Dukungan social terpenting berasal dari orang terdekat seperti suami, keluarga, dan sahabat (Smet, 2004). Namun, dukungan suami terkadang tidak diperlukan. Salah satunya karena secara cultural ada pembagian peran, dimana ayah berperan sebagai pencari nafkah sedangkan urusan rumah tangga dan anak-anak seolah-olah telah menjadi tanggung jawab ibu (Yuniardi, 2009).

Berdasarkan data dari Departemen Kesehatan RI pada tahun 2012 jumlah kunjungan balita ke posyandu balita di seluruh Indonesia sejumlah 71,4\%, (Depkes RI, 2012).Di Jawa Timur cakupan penimbangan balita tercatat sebesar 80,36 \% (Kemenkes RI, 2013). Data dari Dinas Kesehatan Jombang tahun 2014 jumlah kunjungan ibu dan balita datang ke Posyandu D/S (Datang/Sasaran) se Kabupaten Jombang sebesar $75,28 \%$. Hal ini menunjukkan bahwa tingkat keaktifan di posyandu balita masih rendah dibandingkan dengan standar pelayanan minimal $80 \%$. Berdasarkan data di Kabupaten Jombang jumlah cakupan (D/S) balita tertinggi tahun 2014 berada di wilayah kerja Puskesmas Gambiran (95,56\%), sedangkan cakupan terendah berada di wilayah kerja Puskesmas Pulolor $(60,69 \%)$.

Keberadaan posyandu dalam masyarakat memegang peranan penting, namun masih banyak anggota masyarakat yang belum memanfaatkannya secara maksimal. Beberapa kendala yang di hadapi terkait dengan kunjungan balita ke posyandu salah satunya adalah tingkat pemahaman suami terhadap manfaat posyandu. Hal itu akan berpengaruh pada keaktifan ibu dalam mengunjungi setiap kegiatan posyandu. Keaktifan ibu balita dalam kegiatan posyandu merupakan salah satu factor pendukung yang sangat di perlukan

Kunjungan balita di posyandu berkaitan dengan peran ibu sebagai orang yang paling bertanggung jawab terhadap kesehatan balitanya, karena balita sangat bergantung dengan ibunya. Dukungan social merupakan dukungan emosional yang berasal dari suami anggota keluarga, bahkan pemberi keperawatan kesehatan yang membantu individu ketika suatu masalah muncul (Videbeck, 2008).Untuk mengatasi masalah tersebut salah satunya adalah memberikan pengarahan kepada para masyarakat tentang pentingnya posyandu bagi balita dan memberikan dukungan kepada ibu balita yang dapat diberikan oleh suami, kader dan petugas kesehatan dalam bentuk-bentuk dukungan emosional, dukungan penghargaan, dukungan instrumental, dukungan informasi dan dukungan penilaian agar ibu balita yang mau berpartisipasi dalam kegiatan posyandu dan dapat menikmati hasil dari program posyandu tersebut.

\section{METODE PENELITIAN}

Penelitian ini dilakukan di dusun pulo lapangan desa pulo lor kecamatan jombang kabupaten jombang. Waktu penelitian dilaksanakan pada tanggal 10 April - 15 April 2017. Populasi dalam penelitian ini adalah semua ibu yang memiliki balita di dusun pulo lapangan desa pulo lor kecamatan jombang kabupaten jombang sebanyak 93orang, dengan jumlah sampel 47 orang. Teknik yang digunakan adalah simple random sampling.

Alat ukur yang digunakan adalah kuesioner dan KMS. 
Tabel 1. Dsitribusi Frekuensi Data Umum responden di Dusun Pulo Lapangan Desa Pulo Lor Kecamatan Jombang Kabupaten Jombang Tahun 2017

\begin{tabular}{|c|c|c|c|}
\hline No & Kategori & Frekuensi & Presentase $(\%)$ \\
\hline \multirow[t]{4}{*}{1} & Umur Suami & & \\
\hline & $<20$ tahun & 0 & 0 \\
\hline & $21-35$ tahun & 28 & 59,6 \\
\hline & $>35$ tahun & 19 & 40,4 \\
\hline \multirow[t]{4}{*}{2} & Pendidikan & & \\
\hline & SD-SMP & 11 & 23,4 \\
\hline & SMA & 29 & 61,7 \\
\hline & PT & 7 & 14,9 \\
\hline \multirow[t]{6}{*}{3} & Pekerjaan & & \\
\hline & Petani & 1 & 2,1 \\
\hline & Swasta & 19 & 40,4 \\
\hline & Wiraswasta & 20 & 42,6 \\
\hline & PNS atau Militer & 3 & 6,4 \\
\hline & Lain-lain & 4 & 8,5 \\
\hline \multirow[t]{4}{*}{4} & Umur Istri & & \\
\hline & $<20$ tahun & 1 & 2,1 \\
\hline & 21-35 tahun & 34 & 72,3 \\
\hline & $>35$ tahun & 12 & 25,5 \\
\hline \multirow[t]{4}{*}{5} & Pendidikan Istri & & \\
\hline & SD-SMP & 7 & 14,9 \\
\hline & SMA & 32 & 68,1 \\
\hline & PT & 8 & 17,0 \\
\hline \multirow[t]{3}{*}{6} & Pekerjaan Istri & & \\
\hline & Bekerja & 11 & 23,4 \\
\hline & Tidak Bekerja & 36 & 76,6 \\
\hline \multirow[t]{3}{*}{7} & Informasi & & \\
\hline & Pernah & 46 & 97,9 \\
\hline & Tidak pernah & 1 & 2,1 \\
\hline \multirow[t]{4}{*}{8} & Sumber Informasi & & \\
\hline & Petugas kesehatan & 41 & 87,2 \\
\hline & Majalah & 1 & 2,1 \\
\hline & Radio/TV & 4 & 8,5 \\
\hline
\end{tabular}

Tabel 2 Distribusi frekuensi responden berdasarkan dukungan sosial suami menurut jenis dukungan di Dusun Pulo Lapangan Desa Pulo Lor Kecamatan Jombang Kabupaten Jombang tahun 2017

\begin{tabular}{clc}
\hline No & \multicolumn{1}{c}{ Kategori } & $\%$ \\
\hline 1 & Dukungan Instrumental & 25,70 \\
2 & Dukungan Informasional & 24,50 \\
3 & Dukungan Penilaian & 23,34 \\
4 & Dukungan Emosional & 26,46 \\
& Jumlah & 100 \\
\hline
\end{tabular}

(Sumber : data primer, 2017)

Tabel 3 Distribusi frekuensi responden berdasarkan dukungan sosial suami di Dusun Pulo Lapangan Desa Pulo Lor Kecamatan Jombang Kabupaten Jombang tahun 2017

\begin{tabular}{|c|c|c|c|}
\hline No & Kategori & Frekuensi & Persentase (\%) \\
\hline 1 & Mendukung & 36 & 76,6 \\
\hline 2 & Tidak Mendukung & 11 & 23,4 \\
\hline & Jumlah & 47 & 100 \\
\hline
\end{tabular}


Tabel 4 Distribusi frekuensi responden berdasarkan Keaktifan Ibu di Dusun Pulo Lapangan Desa Pulo Lor Kecamatan Jombang Kabupaten Jombang tahun 2017

\begin{tabular}{clcc}
\hline No & Kategori & frekuensi & Persentase (\%) \\
\hline 1 & Aktif $(\geq 8$ kali) & 35 & 74,5 \\
2 & Tidak Aktif $(\leq 8$ kali) & 12 & 25,5 \\
& Jumlah & 47 & 100 \\
\hline (Sumber $:$ data primer, 2017) & &
\end{tabular}

Tabel 5 Tabulasi silang hubungan dukungan sosial suami dengan keaktifan ibu membawa balita ke Posyandu Dahlia II di Dusun Pulo Lapangan Desa Pulolor Kecamatan Jombang Kabupaten Jombang pada tangal 10 April-15 April 2017

\begin{tabular}{|c|c|c|c|c|c|c|c|}
\hline \multirow{3}{*}{ No } & \multirow{3}{*}{ Dukungan Sosial Suami } & \multicolumn{4}{|c|}{ Keaktifan Ibu } & \multirow{2}{*}{\multicolumn{2}{|c|}{ Jumlah }} \\
\hline & & \multicolumn{2}{|c|}{ Aktif } & \multicolumn{2}{|c|}{ Tidak Aktif } & & \\
\hline & & $\mathrm{f}$ & $\%$ & $\mathrm{f}$ & $\%$ & $\mathrm{f}$ & $\%$ \\
\hline 1 & Mendukung & 33 & 70,2 & 3 & 6,4 & 36 & $\overline{76,6}$ \\
\hline 2 & Tidak Mendukung & 2 & 4,3 & 9 & 19,1 & 11 & 23,4 \\
\hline & Jumlah & 35 & 74,5 & 12 & 25,4 & 47 & 100 \\
\hline
\end{tabular}

Tabel 4.12 menunjukkan bahwa, responden yang mendapat dukungan sosial dari suami hampir seluruhnya $(70,2 \%)$ sejumlah 33 orang aktif membawa balitanya ke posyandu yaitu. Sedangkan responden yang tidak mendapat dukungan sosial dari suami hampir seluruhnya $(19,1 \%)$ sejumlah 9 orang tidak aktif membawa balitanya ke posyandu

\section{PEMBAHASAN}

\section{Dukungan Sosial Suami}

Hasil penelitian menunjukan bahwa dukungan sosial suami dapat diketahui dari tabel 4.10 di dapatkan hampir seluruhnya $(76,6 \%)$ dukungan sosial suami mendukung. Keadaan tersebut dimungkinkan dipengaruhi oleh usia, tingkat pendidikan, pekerjaan (pengetahuan).

Menurut friedman (2006) bentukbentuk dukungan sosial suami yang dapat diberikan untuk ibu adalah bantuan materi, informasi, emosional support, dan penghargaan. Adanya dukungan sosial suami dapat memberikan motivasi ibu untuk aktif membawa balita ke posyandu. Dukungan sosial dari lingkungan sekitar ibu, mempunyai peran yang besar terhadap keaktifan ibu ke posyandu. Dukungan sosial yang sangat berasal dari orang terdekat ibu, orang terdekat tersebut adalah suami (Soetjiningsih, 2010).

Sesuai dengan hasil penelitian maka peneliti berpendapat bahwa dukungan sosial dari suami berupa aspek emosional, informasi, instrumental, dan penilaian. Dukungan informasi berasal dari pengetahuan, dukungan penghargaan melalui pemecahan masalah, dan dukungan emosional berupa perhatian terhadap ibu untuk aktif ke posyandu. Sedangkan di masyarakat dukungan tersebut sangat dipengaruhi dan pengalaman.

Tabel 4.1 menunjukkan bahwa sebagian besar $(59,6 \%)$ suami berumur 21-35 tahun.

Umur yaitu usia individu yang terhubung mulai saat dilahirkan sampai dengan berulang tahun (Nursalam, 2003). Umur mempengaruhi daya tangkap dan pola pikir seseorang. Semakin bertambah umur akan semakin berkembang pula daya tangkap dan pola pikirnya, sehingga pengetahuan yang diperoleh semakin banyak (Notoatmodjo, 2003).

Seorang suami mempunyai peranan penting dalam memberikan motivasi ibu agar datang pada setiap kegiatan posyandu. Dukungan dari orang terdekat seperti suami, keluarga dan lingkungan sekitar memberikan peran yang besar dalam memotivasi ibu untuk aktif dalam kegiatan posyandu. 
Tabel 4.2 menunjukkan bahwa sebagian besar $(61,7 \%)$ suami berpendidikan SMA.

Pendidikan merupakan salah satu faktor yang berperan pada pembentukan perilaku suami dalam memberikan dukungan pada istrinya untuk menjaga kesehatan keluarga (Santoso, 2010). Suami yang mempunyai pendidikan yang baik maka suami dapat menerima segala informasi dari luar terutama tentang menjaga kesehatan anaknya ( Soetjiningsih, 1998).

Pendidikan suami membentuk motivasi suami untuk untuk memberikan dukungan pada istrinya. Keadaan ini akan mempengaruhi pengetahuan suami tentang pentingnya kegiatan posyandu, maka suami akan memberikan dukungan pada ibuiu untuk datang pada kegiatan posyandu untuk memantau pertumbuhan dan perkembangan balitanya.

Tabel 4.3 menunjukkan bahwa hampir setengahnya $(42,6 \%)$ pekerjaan suami wiraswasta.

Pekerjaan merupakan salah satu bentuk interaksi dengan orang lain dalam suatu pekerjaan membentuk suatu wawasan yang diperoleh dari informasi (Azwar, 2011). Kesibukan suami yang bekerja akan semakin dikit pengetahuan yang didapatkan. Individu yang berbeda pekerjaan mempunyai kecenderungan yang berbeda pula dalam menggunakan pelayanan kesehatan (Notoatmodjo, 2003).

Pekerjaan suami dapat mempengaruhi dalam memberikan informasi tentang kegiatan posyandu. Suami biasanya sibuk bekerja sehingga jarang bias mengantar ibu ke posyandu, namun suami dapat mencari informasi tentang kegiatan posyandu sehingga timbul kesadaran untuk mengingatkan ibu selalu aktif datang ke posyandu.

2. Keaktifan ibu membawa balita ke posyandu
Hasil penelitian menunjukan hampir seluruhnya $(74,5 \%)$ aktif. Keadaan tersebut dimunkinkan dipengaruhi oleh beberapa faktor yaitu usia, pendidikan, status pekerjaan, dan tingkat pengetahuan.

Tabel menunjukkan bahwa sebagian besar $(72,3 \%)$ responden berumur 21-35 tahun.

Faktor umur berperan pada pembentukan kedewasaan seseorang, semakin dewasa seseorang maka akan semakin mampu menetukan tindakan yang harus diambil (Hurlock, 2009). Semakin dewasa usia seseorang maka tingkat kematangan berfikir dan bertindaknya semakin baik, hal ini dikarenakan bertambahnya pengalaman dan wawasan (Tunjungsari, 2012). Umur mendukung penyerapan informasi dalam meningkatkan minatnya untuk melakukan kunjungan ke posyandu. Dengan bertambahnya usia seseorang akan memiliki kemampuan kognitif dan penilaian moral lebih baik sehingga mendorong ibu untuk mengambil keputusan dalam berperan aktif membawa balita ke posyandu.

Tabel menunjukkan bahwa sebagian besar $(68,1 \%)$ pendidikan responden SMA.

Pendidikan merupakan hal penting untuk meningkatkan pengetahuan karena pengetahuan merupakan factor yang mendahului atai motivasi dari perilaku seseorang (Notoatmodjo, 2003). Tingkat pendidikan yang tinggi akan memudahkan seseorang untuk menyerap informasi dan juga masih tinggi kesadarannya untuk berperan serta, dalam hal ini adalah keaktifan membawa balita ke posyandu (Atmarita, 2004). Pendidikan akan berpengaruh terhadap cara berfikir dalam pengambilan kepuusan seseorang untuk menggunakan pelayannan kesehatan, maka semakin tinggi pendidikan ibu akan semakin baik pula pengetahuan tentang kesehatan.

Tabel menunjykkan bahwa sebagian besar $(76,6 \%)$ responden tidak bekerja. 
Ibu yang bekerja di luar rumah dapat dikatakan tidak dapat pergi ke posyandu karena kegiatan di posyandu dilakukan pada hari dan jam kerja, akan tetapi ada kemungkinan menitipkan pada orang lain untuk dibawa ke posyandu (Tunjungsari, 2012). Jenis pekerjaan seseorng akan berpengaruh terhadap banyaknya waktu luang yang dimilikinya dalam turut serta berbagai kegiatan di masyarakat (Ocbrianto, 2012). Ibu yang bekerja umumnya kegiatan yang menyita waktu. Ibu yang bekerja memiliki waktuyang kurang dalam mengasuh anaknya. Sedangkan ibu yang tidak bekerja mempunyai waktu luan lebih besar dalm memberikan perhatian kepada anaknya dan membawa anaknya ke posyandu.

Tabel menunjukkan bahwa hampir seluruhnya $(87,2 \%)$ responden mendapat informasi dari petugas kesehatan.

Pemberian informasi merupakan salah satu aspek yang berperan pada perubahan perilaku baru, pemberian informasi akan mempengaruhi pada perilaku seseorang terhadap stimulus yang diterimanya. Jika stimulus yang diberikan mendapat perhatian maka akan terjadi suatu perubahan perilaku, dan jika stimulus yang diberikan tidak mendapat perhatian maka tidak akan merubah perilaku seseorang (Notoatmodjo, 2010). Informasi tentang posyandu salah satu aspek yang berperan pada keaktifan ibu membawa ke posyandu, dimana ibu yang memperhatikan jadwal kegiatan posyandu. Ibu yang mendapat informasi dari petugas kesehatan akan meningkatkan ibu aktif datang ke kegiatan posyandu.

3. Hubungan dukungan social dengan keaktifan ibu membawa balita ke posyandu

Hasil uji statistik Chi-Square di dapatkan continuity correction $\rho$ value yang diperoleh dapat dilihat pada Person Chi-Square yaitu $\rho$ value $=0,000$ dimana nilai $\rho$ value $<\alpha(0,05)$. Dari hasil hitung $0,000<\alpha 0,05$ maka hipotesa Ho di tolak H1 di terima, artinya ada hubungan antara hubungan dukungan sosial suami dengan keaktifan ibu membawa balita ke posyandu dahlia II di dusun pulo lapangan Desa Pulolor Kecamatan Jombang Kabupaten Jombang. Nilai kolerasi Chi-Square 0,581 menurut tabel interpretasi adalah termasuk dalam rentang 0,40-0,599 yaitu interpretasi sedang.

Teori Lawrence Green menyebutkan bahwa dukungan merupakan salah satu faktor penguat (reinforcing factor) yang dapat mempengaruhi seseorang dalam berperilaku, sehingga dukungan sosial memiliki kekuatan sebagai pencegahan atau dapat mendorong seseorang berperilaku sehat. Jenis dukungan sosial yang diberikan berupa dukungan emosional, dukungan informasional, dukungan instrumental, dan dukungan penghargaan (Notoatmodjo, 2010).

Dukungan sosial adalah kenyamanan secara fisik dan psikologis yang diberikan oleh teman, orang di sekitar lingkungan atau anggota keluarga (Baron \& Byrne, 2005). Dukungan sosial dapat berpengaruh terhadap penilaian individu dalam memandang seberapa berat suatu peristiwa yang terjadi dalam hidupnya, kemudian dapat mempengaruhi pilihan dalam upaya penanggulangan, serta dukungan juga dapat berdampak langsung terhadap perilaku kesehatan. Ibu lebih mudah terpengaruh untuk melakukan perilaku kesehatan yang positif ketika mereka mendapat dukungan dari suami (Montigny, 2006).

Dukungan dari suami dan hubungan yang baik dapat memberikan kontribusi penting pada kesehatan ibu. Hal tersebut akan membuat orang merasa diperhatikan, dicintai, dimuliakan dan dihargai. Dukungan dari suami diperlukan pada kehadiran ibu datang ke posyandu, karena dengan adanya dukungan dari suami maka akan terbentuk motivasi ibu balita hadir dalam kegiatan posyandu. Pada dasarnya dukungan sosial dari suami yang baik 
akan mendorong ibu aktif hadir dalam kegiatan posyandu.

\section{KESIMPULAN DAN SARAN}

Berdasarkan hasil penelitian Hubungan Dukungan Sosial Suami dengan Keaktifan Ibu Membawa Balita Ke Posyandu Dahlia II di Dusun Pulo Lapangan Desa Pulolor Kecamatan Jombang Kabupaten Jombang pada tangal 10 April 15 april 2017, diperoleh kesimpulan sebagai berikut : Ada hubungan dukungan sosial suami dengan keaktifan ibu membawa balita Ke Posyandu Dahlia II di Dusun Pulo Lapangan Desa Pulolor Kecamatan Jombang Kabupaten Jombang yaitu dengan interpretasi sedang.

Disarankan peneliti selanjutya agar meneliti lebih lanjut tentang faktor lain keaktifan ibu membawa balita ke posyandu.

\section{DAFTAR PUSTAKA}

Atmarita. 2004. Pola Asuh dalam Hubungannya dengan status gizi anak balita ditinjau dari Pekerjaan, pendapatan dan pengeluaran orang tua di daerah Sulawesi selatan. artikel
Baron, R.A \& Byrne, D. 2010. Psikologi sosial (terjemahan Djuwita, R dkk). Jakarta : Erlangga

Departemen kesehatan RI, 2010. Riset Kesehatan Dasar 2010. Jakarta : Departemen Kesehatan RI

Dinkes Jombang. 2013. Data Kunjungan Balita Ke Posyandu. Dinkes Jombang

Friedman, M Marilyn. 1998. Keperawatan Keluarga : Teori dan Praktik. Jakarta : EGC

Elizabeth, Hurlock. 2009. Psikologi Perkembangan Rentang Kehidupan. Jakarta: EGC

Kementrian Kesehatan RI. 2013. Profil Kesehatan Povinsi Jawa Timur 2013. surabaya : Kementrian Kesehatan RI

Notoadmodjo, S. 2003. Ilmu Kesehatan Masyarakat. Jakarta: Rineka Cipta. 2010. Promosi Kesehatan Teori dan Aplikasi. Jakarta : Rineka Cipta

Suharso dan Retnoningsih. 2008. Sumber Daya Manusia. Jakarta : Pustaka Pelajar.

Videbeck, Shella L, 2008. Buku Ajar Keperawatan Jiwa. Jakarta : Buku Kedokteran EGC 